\title{
Inhibition of liver methionine adenosyltransferase gene expression by 3-methylcolanthrene: protective effect of $S$-adenosylmethionine
}

\author{
M. Victoria Carretero ${ }^{\mathrm{a}, 1}$, Maria U. Latasa ${ }^{\mathrm{a}, 1}$, Elena R. Garcia-Trevijano ${ }^{\mathrm{a}}$, \\ Fernando J. Corrales $^{\mathrm{a}}$, Conrad Wagner ${ }^{\mathrm{b}}$, Jose M. Mato ${ }^{\mathrm{a}}$, Matias A. Avila ${ }^{\mathrm{a}, *}$ \\ a División de Hepatología y Terapia Génica, Facultad de Medicina (Ed. Los Castaños), Universidad de Navarra, C/ Irunlarrea 1, \\ 31008 Pamplona, Spain \\ ${ }^{\mathrm{b}}$ Vanderbilt University, School of Medicine, Department of Biochemistry, 620 Light Hall, 21st Avenue South, Nashville, TN 37232, USA
}

Received 4 September 2000; accepted 1 December 2000

\begin{abstract}
Methionine adenosyltransferase (MAT) is an essential enzyme that catalyzes the synthesis of $S$-adenosylmethionine (AdoMet), the most important biological methyl donor. Liver MAT I/III is the product of the MAT1A gene. Hepatic MAT I/III activity and MAT1A expression are compromised under pathological conditions such as alcoholic liver disease and hepatic cirrhosis, and this gene is silenced upon neoplastic transformation of the liver. In the present work, we evaluated whether MATIA expression could be targeted by the polycyclic arylhydrocarbon (PAH) 3-methylcholanthrene (3-MC) in rat liver and cultured hepatocytes. MAT1A mRNA levels were reduced by 50\% following in vivo administration of 3-MC to adult male rats (100 mg/kg, p.o., 4 days' treatment). This effect was reproduced in a time- and dose-dependent fashion in cultured rat hepatocytes, and was accompanied by the induction of cytochrome P450 1A1 gene expression. This action of 3-MC was mimicked by other PAHs such as benzo[ $a]$ pyrene and benzo[ $e]$ pyrene, but not by the model arylhydrocarbon receptor (AhR) activator 2,3,7,8-tetrachlorodibenzo-p-dioxin. 3-MC inhibited transcription driven by a MAT1A promoter-reporter construct transfected into rat hepatocytes, but MAT1A mRNA stability was not affected. We recently showed that liver MAT1A expression is induced by AdoMet in cultured hepatocytes. Here, we observed that exogenously added AdoMet prevented the negative effects of 3-MC on MAT1A expression. Taken together, our data demonstrate that liver MATlA gene expression is targeted by PAHs, independently of AhR activation. The effect of AdoMet may be part of the protective action of this molecule in liver damage. (C) 2001 Elsevier Science Inc. All rights reserved.
\end{abstract}

Keywords: Liver damage; Methionine metabolism; Polycyclic aromatic hydrocarbons; $S$-adenosylmethionine; Methionine adenosyltransferase

\section{Introduction}

Liver methionine metabolism starts with the formation of AdoMet, which is the most important methyl donor in biological methylations, including all detoxifying reactions [1]. In addition, AdoMet participates in polyamine biosynthesis and is a precursor for the synthesis of GSH in the 677.

* Corresponding author. Tel.: +34-948-425-678; fax: +34-948-425-

E-mail address: maavila@unav.es (M.A. Avila).

${ }^{1}$ Both authors made an equal contribution to this work.

Abbreviations: ActD, actinomycin D; AdoMet, $S$-adenosylmethionine; $\mathrm{AhR}$, arylhydrocarbon receptor; $\mathrm{B}[a] \mathrm{P}$, benzo $[a]$ pyrene; $\mathrm{B}[e] \mathrm{P}$, benzo[e]pyrene; CYP1A1, cytochrome P450 1A1; EGSH, ethyl ester of glutathione; MAT, methionine adenosyltransferase; 3-MC, 3-methylcholanthrene; NAC, $N$-acetylcysteine; $\alpha$-NF, $\alpha$-naphthoflavone; PAH, polycyclic arylhydrocarbon; TCDD, 2,3,7,8-tetrachlorodibenzo- $p$-dioxin. liver, from where this compound is excreted into circulation and bile [2]. Sulfate groups for conjugation reactions are also derived from AdoMet through the transsulfuration pathway [1]. The synthesis of AdoMet is catalyzed by MAT (EC 2.5.1.6). There are two genes coding for MAT in mammals: MAT1A and MAT2A, and their products are known as MAT I/III and MAT II, respectively [3]. MAT1A is expressed only in the adult liver, while MAT2A is expressed outside this organ and in the fetal and transformed hepatocytes [4]. Hepatic MAT activity and expression are impaired in pathological conditions such as alcoholic and viral liver cirrhosis and in experimental models of liver injury in response to ethanol, carbon tetrachloride, bacterial lipopolysaccharide, and hypoxia [4-6]. Additionally, administration to rats of chemical carcinogens, such as 2-acetylaminofluorene and diethylnitrosamine, also compromise liver AdoMet synthesis $[7,8]$. 
In addition to the relevance of the numerous reactions in which AdoMet participates, the pathological importance of impaired AdoMet production can be inferred from the protective effects of exogenously administered AdoMet. This has been observed in experimental models of liver damage induced by carbon tetrachloride, galactosamine, ethanol, cytokines, paracetamol, and thioacetamide [4]. Furthermore, in a recently reported clinical trial, AdoMet was found to improve survival of alcoholic cirrhotic patients [9]. However, the molecular mechanisms behind the hepatoprotective actions of AdoMet are not completely known. In this regard, we have recently demonstrated the key role played by AdoMet in the preservation of MATIA gene expression in rat hepatocytes [10], which is known to be down-regulated in the human and rat cirrhotic liver $[5,11]$.

PAHs such as 3-MC are widely distributed carcinogens that are actively metabolized in the liver [12]. PAHs have been found to cause alterations in liver metabolism, such as impairment in phospholipid methylation [13] and phosphatidylcholine biosynthesis [14], and to increase lipid peroxidation and liver damage in response to paracetamol [15]. These compounds exert profound effects on the expression of a variety of genes, in particular those involved in drug metabolism, the induction of CYPIAl being among the best-characterized responses [16-18]. In addition to the well-known induction of gene expression by PAHs, these chemicals have also been shown to impair the expression of other genes, such as $\gamma$-glutamyltranspeptidase [19] and the drug-metabolizing enzymes cytochrome CYP2C11 [20-24] and hydroxysteroid sulfotransferase-a [25]. However, the molecular mechanisms behind PAH-mediated down-regulation of gene expression are less well understood. Given the central role played by MAT1A in AdoMet synthesis and one-carbon metabolism, together with the relevance of this metabolic pathway in the preservation of liver function, we have now investigated the response of this gene to this family of carcinogens in vivo and in a model of cultured rat hepatocytes.

\section{Materials and methods}

\subsection{Materials}

3-MC, $\mathrm{B}[a] \mathrm{P}, \mathrm{B}[e] \mathrm{P}, \alpha-\mathrm{NF}$, triamcinolone, and NAC were from Sigma Chemical Co. TCDD was purchased from Cambridge Isotope Laboratories. AdoMet, in the stable form of sulfate- $p$-toluenosulfonate salt produced by Knoll Farmaceutici, was provided by Europharma. ActD, restriction endonucleases, and collagenase were from Boehringer Mannheim, while culture media and supplements were from Life Technologies. Collagen type I from rat tail was purchased from Collaborative Research-Biomedical Products. EGSH was a gift from Dr. M. Martin-Lomas (CSIC, Sevilla, Spain). All other reagents and chemicals were from Sigma Chemical, Merck, and Fluka.

\subsection{Animals and treatment}

Male Wistar rats $(200-250 \mathrm{~g})$ were used for in vivo experiments. Animals received a daily oral dose of 3-MC $(100 \mathrm{mg} / \mathrm{kg})$ prepared in corn oil $(26.5 \mathrm{mg} / \mathrm{mL})$, while controls were treated with vehicle alone. After 4 days of treatment, animals were killed and liver samples taken and frozen in liquid nitrogen. The duration of this treatment was in the range of that used in other studies, including gene expression studies, in which the effects of PAHs have been assessed in rat liver [24-26]. Animals were treated humanely, and study protocols were in compliance with our institution's guidelines for use of laboratory animals.

\subsection{Determination of AdoMet levels in rat liver samples}

Liver tissue (100 mg) was homogenized and deproteinized in $0.4 \mathrm{M}$ perchloric acid and centrifuged at $12,000 \mathrm{~g}$ for $30 \mathrm{~min}$ at $4^{\circ}$. Supernatants were analyzed by reversed-phase high performance liquid chromatography as described previously [27].

\subsection{Rat hepatocyte isolation and cell culture}

Liver cells were isolated from male Wistar rats (200-250 g) by collagenase perfusion as described previously [6]. Cells were plated onto $60-\mathrm{mm}$ collagen-coated culture dishes at a density of $3 \times 10^{6}$ cells per dish. Cultures were maintained in RPMI-1640 medium supplemented with $10 \%$ fetal calf serum, $2 \mathrm{mM}$ glutamine, $50 \mathrm{mM}$ penicillin, and 50 $\mathrm{mg} / \mathrm{mL}$ of streptomycin sulfate. After a 2-hr incubation, the culture medium was removed and cultures were re-fed the same medium with $2.5 \%$ fetal calf serum. Cells were maintained at $37^{\circ}$ in a humidified incubator containing $21 \%$ oxygen and 5\% carbon dioxide in air. All experiments were started $2 \mathrm{hr}$ post-killing. Cellular viability was tested by the trypan blue exclusion test, and no significant differences were found between controls and any of the different treatments performed.

\subsection{RNA isolation and Northern blot analysis}

Total RNA was isolated by the guanidinium thiocyanate method [28]. Aliquots $(20 \mu \mathrm{g})$ of total RNA were sizefractionated by electrophoresis in 1\% agarose gel under denaturing conditions. RNAs were then blotted and fixed to Nytran membranes. Prehybridization and hybridization were performed as described previously [29]. MATIA mRNA levels were measured using a 2.2-kb EcoRI fragment of rat MATIA cDNA [30]. CYPIAI mRNA levels were determined using a $0.7-\mathrm{kb} P s t \mathrm{I}$ fragment from mouse CYPIA1 cDNA (a gift from Dr. P. Fernández-Salguero, Universidad de Extremadura, Spain) [31]. Equal loading of the RNA gels was assessed by hybridization with a probe specific for $18 \mathrm{~S}$ rRNA. The probes were labeled with $\left[\alpha-{ }^{32} \mathrm{P}\right] \mathrm{dCTP}(3000 \mathrm{Ci} / \mathrm{mmol}$; Amersham Pharmacia Bio- 
tech) by ramdom priming using the RediPrime DNA Labeling System (Amersham Pharmacia Biotech). Specific activity was usually $5 \times 10^{8} \mathrm{cpm} / \mu \mathrm{g}$ of DNA. Quantitation was performed by scanning densitometry of the $\mathrm{x}$-ray films.

\subsection{Immunoblot analysis}

For determination of MAT I/III protein levels, hepatocytes were lysed in RIPA (radioimmunoprecipitation assay) buffer (10 mM Tris-HCl, pH 7.4, $150 \mathrm{mM} \mathrm{NaCl}, 1 \%$ Triton $\mathrm{X}-100,1 \%$ sodium deoxycholate, $0.1 \%$ SDS, $0.1 \mathrm{mM}$ phenylmethylsulfonyl fluoride, and $1 \mathrm{mM}$ benzamidine). The homogenate was centrifuged for $30 \mathrm{~min}$ at $10,000 \mathrm{~g}$, and supernatants collected. Equal amounts of protein $(20 \mu \mathrm{g})$ were subjected to $10 \%$ SDS-PAGE, and then electrophoretically transferred to nitrocellulose membranes. Immunodetection of MAT I/III was performed using a rabbit anti-rat MAT I/III antiserum [32] and a horseradish peroxidase-conjugated secondary antibody. Blots were developed by enhanced chemoluminescence according to the manufacturer's instructions (Dupont).

\subsection{Transient transfections of cultured rat hepatocytes}

Hepatocytes were seeded as described above in collagencoated multiwell dishes $\left(5 \times 10^{5}\right.$ cells per 30 -mm well $) 12$ $\mathrm{hr}$ before transfections. Cells were transfected with $5 \mu \mathrm{g}$ of a MATIA promoter-luciferase construct encompassing 1.4 $\mathrm{kb}$ of the $5^{\prime}$-flanking region of this gene (nucleotides -1405 to +65 ) [33], using the TFx50 reagent (Promega) according to the manufacturer's instructions. Five micrograms of the $\beta$-galactosidase expression vector $\mathrm{pCH} 110$ (Amersham Pharmacia Biotech) was included as an internal standard of transfection efficiency. After $24 \mathrm{hr}$, cells were harvested and luciferase and galactosidase activities were determined as described [33]. Values reported are means of three independent experiments performed in triplicate.

\subsection{Statistics}

The data are the means \pm SEM of at least two independent experiments done in triplicate. Statistical significance was estimated with Student's $t$-test. A $P$ value of $<0.05$ was considered significant.

\section{Results}

\subsection{Effect of 3-MC on rat liver MAT1A gene expression in vivo}

We first examined the effect of 3-MC treatment on rat liver MAT1A gene expression. For this purpose, animals received a daily oral dose of $100 \mathrm{mg} / \mathrm{kg}$ of $3-\mathrm{MC}$ for a period of four days, then liver MATIA mRNA levels were determined by Northern blotting. As shown in Fig. 1A, liver
A

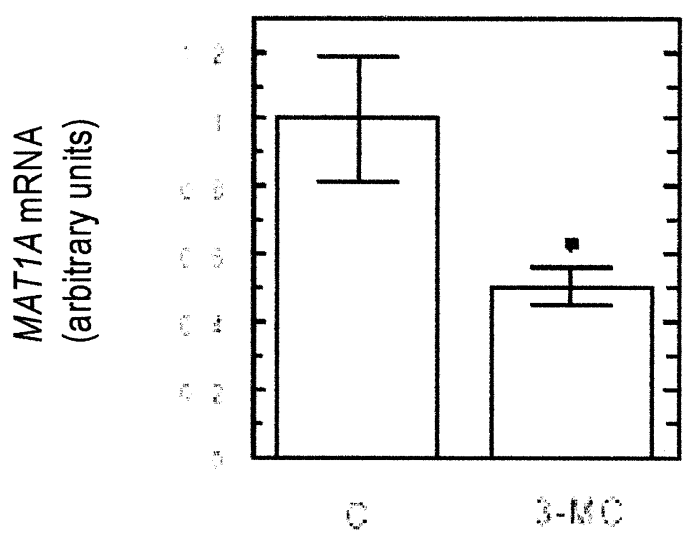

B

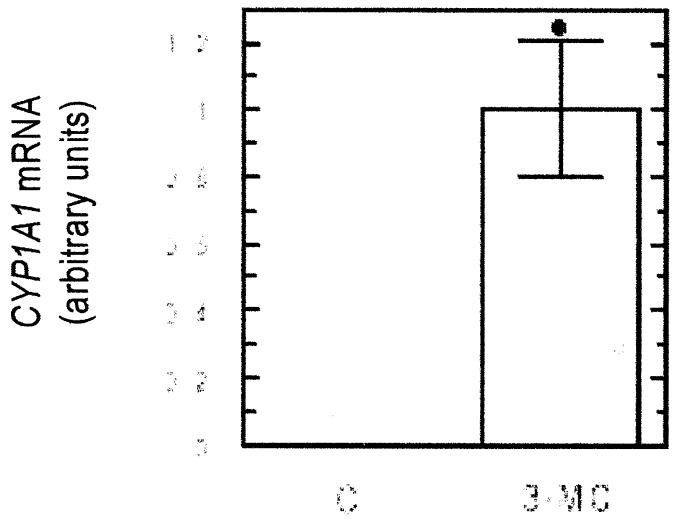

Fig. 1. Expression of MAT1A and CYP1A1 in the liver of 3-MC-treated rats. Animals were treated for 4 days with a daily oral dose of $100 \mathrm{mg} / \mathrm{kg}$ of 3-MC in corn oil, while controls received the same volume of vehicle. Northern blot analysis of (A) MAT1A and (B) CYP1A1 mRNA levels in the liver of control (C) and 3-MC-treated (3-MC) rats. 18S rRNA hybridization was performed as loading control. Data are means \pm SEM $(\mathrm{N}=3$ for the control group; $\mathrm{N}=6$ for the 3 -MC group) $(* P<0.05$ compared with the control value).

MATIA expression was reduced by about $50 \%$ in response to 3-MC as compared to the levels found in control animals. The duration of this treatment was not long enough to detect changes in AdoMet levels $(37.93+4.02 \mathrm{pmol} / \mathrm{mg}$ of liver tissue in controls versus $33.63+7.26 \mathrm{pmol} / \mathrm{mg}$ of liver tissue in 3-MC-treated animals). In order to monitor the effectiveness of our treatment, the expression of CYPIAl, probably the best-characterized target gene for xenobiotic action, was determined in the liver of control and 3-MCtreated animals. As represented in Fig. 1B, 3-MC treatment resulted in the expected induction of CYP1A1 mRNA.

\subsection{Effect of 3-MC on MAT1A gene expression in isolated rat hepatocytes}

In order to further characterize 3-MC effects on MATIA expression, isolated rat hepatocytes in culture were treated 
A

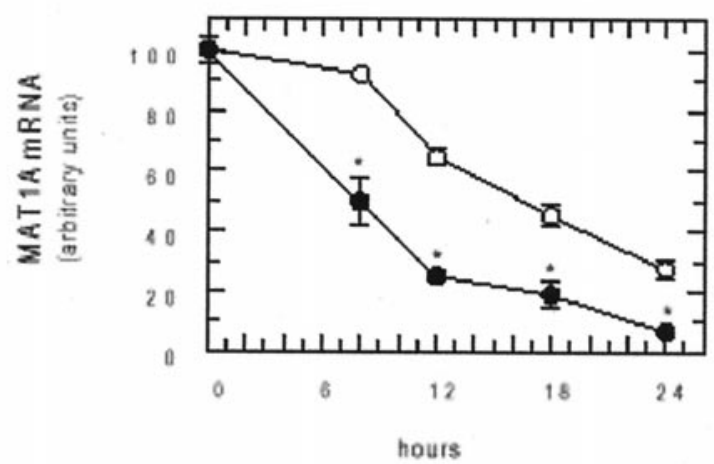

B

MAT I/III protein

$\frac{12 h}{0 \sum_{\infty}^{0}} \frac{24 h}{\sum_{\dot{m}}^{0}} \frac{48 h}{\sum_{j}^{0}}$

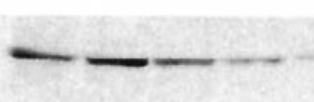

C

$\begin{array}{llllll}0 & 0.01 & 0.1 & 1 & 5 & 3-\mathrm{MC}(\mu \mathrm{M})\end{array}$

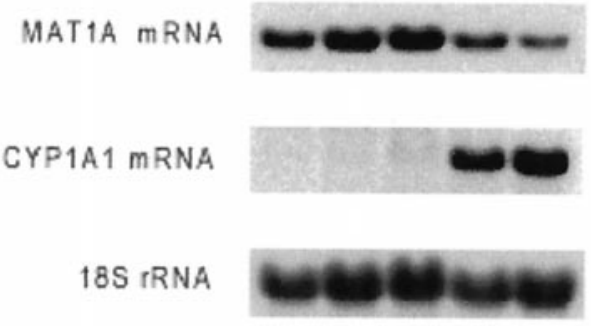

Fig. 2. Effect of 3-MC on MAT1A expression in cultured hepatocytes. (A) Primary cultures of rat hepatocytes were treated for different periods of time with 3-MC $(5 \mu \mathrm{M})$ (solid circles) or DMSO (controls) (open circles) and MATIA mRNA levels were analyzed by Northern blotting. Data are the means \pm SEM of three independent experiments done in triplicate $(* P<$ 0.05 compared with the control value). (B) Western blot analysis of MAT $\mathrm{I} / \mathrm{III}$ protein in hepatocytes treated for different periods of time with 3-MC $(5 \mu \mathrm{M})$ or DMSO (a representative blot of three independent experiments is shown). (C) Northern blot analysis of MAT1A and CYP1A1 mRNA levels in hepatocytes treated for $24 \mathrm{hr}$ with different concentrations of 3-MC (a representative blot of three independent experiments is shown). $18 \mathrm{~S}$ rRNA hybridization was performed as loading control in Northern blotting experiments.

with 3-MC $(5 \mu \mathrm{M})$ for different periods of time. As previously described $[6,10]$, a time-dependent decrease in MATIA mRNA levels was observed when hepatocytes were set in culture (Fig. 2A). This situation is common to other liver-specific genes when their expression is measured in cultured hepatocytes [34]. However, in response to 3-MC a pronounced decrease in MATIA mRNA content (50\% with respect to control value) was already detected after $7 \mathrm{hr}$ of treatment, while controls were still comparable to those present at the onset of cultures (time 0) (Fig. 2A). MAT I/III protein levels were also measured under the same conditions. Fig. 2B shows a representative Western blot which shows how MAT I/III protein levels followed the changes reported above for its mRNA, being almost undetectable after $48 \mathrm{hr}$ of treatment with 3-MC $(5 \mu \mathrm{M})$. The effect of 3-MC on MATIA expression was dose-dependent, being already observed at $1 \mu \mathrm{M}$, and was accompanied by the concomitant induction of CYPIA1 mRNA (Fig. 2C).

\subsection{Lack of involvement of the AhR pathway in 3-MC-mediated down-regulation of MAT1A expression}

At this point, it was important to know if the observed effects of 3-MC on MATIA expression were mediated through the interaction of this compound with the AhR receptor, which is responsible for many of the gene regulatory events elicited by xenobiotics. For this purpose, hepatocytes were treated for $24 \mathrm{hr}$ with $1 \mu \mathrm{M}$ TCDD, a potent agonist of the AhR receptor used at a high concentration in the culture medium. As shown in Fig. 3, this treatment induced no changes in MATIA mRNA levels, while there was a substantial induction of CYPIAl gene expression. Further evidence for the lack of involvement of the AhR in MATIA down-regulation by 3-MC was obtained when hepatocytes were treated simultaneously with this agent (5 $\mu \mathrm{M})$ and the AhR antagonist $\alpha-\mathrm{NF}(20 \mu \mathrm{M})$ [35] for $24 \mathrm{hr}$. Under these conditions, 3-MC still exerted its negative effect on MATIA mRNA levels, while $\alpha$-NF effectively blocked the induction of CYPIAl mRNA (data not shown). Interestingly, other compounds structurally related to 3-MC, such as $\mathrm{B}[a] \mathrm{P}$ and $\mathrm{B}[e] \mathrm{P}$, also displayed inhibitory effects on MATIA expression. Fig. 3 shows the effect of 24-hr treatment of cultured hepatocytes with $5 \mu \mathrm{M}$ of $\mathrm{B}[a] \mathrm{P}$ or 20 $\mu \mathrm{M} \mathrm{B}[e] \mathrm{P}$. These treatments resulted in a $65 \%$ and $50 \%$ reduction in MATIA mRNA levels, respectively, while CYPIA transcription was activated as expected. Phenobarbital, another xenobiotic structurally unrelated to PAHs, did not affect MATIA expression after 24-hr incubation at 1 $\mathrm{mM}$ (data not shown).

\subsection{No involvement of impaired glucocorticoid action and the generation of reactive oxygen species in the inhibition of MAT1A gene expression by 3-MC}

Given the prominent role played by glucocorticoids in the maintenance of liver MATIA expression in vivo [36] and the previously reported ability of certain xenobiotics, including 3-MC, to impair glucocorticoid actions [26], we wanted to know if 3-MC could interfere with the effect of these hormones on MATIA gene expression. For this pur- 


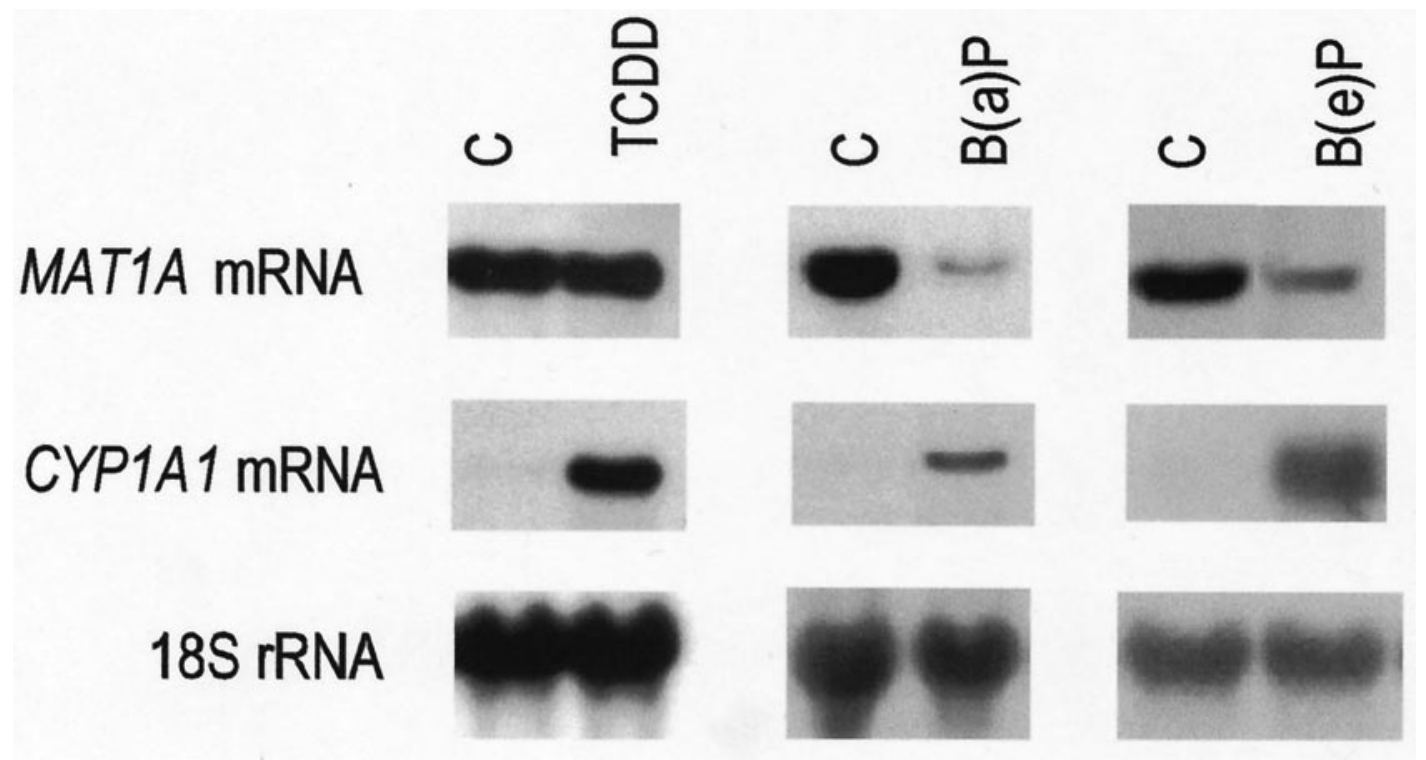

Fig. 3. The inhibitory effect of 3-MC on MAT1A expression is independent of the AhR pathway. Northern blot analysis of MAT1A and CYP1A1 mRNA levels in hepatocytes treated for $24 \mathrm{hr}$ with $\mathrm{TCDD}(1 \mu \mathrm{M}), \mathrm{B}[a] \mathrm{P}(5 \mu \mathrm{M})$, or $\mathrm{B}[e] \mathrm{P}(20 \mu \mathrm{M})$. Control cells were incubated in the presence of DMSO. 18S rRNA hybridization is shown in all cases as loading control. This experiment was repeated three times in duplicate with similar results, and a representative blot is shown.

pose, hepatocytes were treated with 3-MC $(5 \mu \mathrm{M})$ for $24 \mathrm{hr}$ in the presence or absence of $1 \mu \mathrm{M}$ triamcinolone, and then MATIA mRNA levels were quantitated by Northern blotting. As shown in Fig. 4A, 3-MC was able to inhibit the up-regulation of MATIA mRNA levels in response to triamcinolone, although the magnitude of the 3-MC effect was similar to that observed in the absence of the glucocorticoid (about 50\%). In order to determine if 3-MC effects could be due to the impairment of triamcinolone action on MATIA gene expression or if these two agents acted independently, hepatocytes were preincubated with 3-MC $(5 \mu \mathrm{M})$ for $14 \mathrm{hr}$, with the response to the glucocorticoid then tested in control (without 3-MC) and pretreated (with 3-MC) cells by a subsequent incubation for $4 \mathrm{hr}$ in the presence of $1 \mu \mathrm{M}$ triamcinolone. As shown in Fig. 4B, glucocorticoid responsiveness was preserved in hepatocytes that had been pretreated with $3-\mathrm{MC}$, as indicated by the similar response to triamcinolone in terms of MATIA mRNA induction, regardless of the previous presence of the xenobiotic.

It is known that some of the effects exerted by xenobiotics such as 3-MC on the expression of certain genes can be mediated through the generation of reactive oxygen species and the depletion of intracellular GSH $[37,38]$. In order to evaluate whether this situation could be of importance in the down-regulation of MAT1A expression by 3-MC, we incubated cultured rat hepatocytes with $3-\mathrm{MC}$ in the presence of the antioxidants NAC (5 mM) or the cell-permeable ethyl ester of GSH, EGSH ( $5 \mathrm{mM}$ ) for $24 \mathrm{hr}$ and measured MATIA mRNA levels. None of these antioxidants was able to prevent MATIA mRNA down-regulation by 3-MC (data not shown). In addition, treatment with menadione, a wellknown inducer of cellular oxidative stress, did not affect MATIA expression (data not shown).

\subsection{Mechanism of MAT1A mRNA down-regulation by 3-MC}

We studied the mechanisms responsible for the reduction in MATIA steady-state mRNA levels by 3-MC. First, we analyzed whether this compound was able to alter MATIA mRNA stability. For this purpose, hepatocytes were preincubated with the transcriptional inhibitor ActD $(5 \mu \mathrm{g} / \mathrm{mL})$ for $2 \mathrm{hr}$ and then, without removing ActD from the culture medium, half of the plates received 3-MC $(5 \mu \mathrm{M})$ or were left untreated. MATIA mRNA levels were measured at different time points by Northern blotting. As shown in Fig. $5 \mathrm{~A}$, when overall transcription was blocked, MAT1A mRNA levels decayed at the same rate in control and 3-MC-treated cells, suggesting that MATIA mRNA stability was not compromised by this agent. This result was further confirmed when rat hepatoma cells were transiently transfected with an expression vector encompassing the full-length MATIA cDNA and transfectants were treated with 3-MC. In agreement with our observations using ActD, the steady-state levels of MATIA mRNA encoded by the transfected construct were not reduced in response to 3-MC (data not shown).

We next examined if MATIA transcription could be targeted by 3-MC. To this end, cultured hepatocytes were transiently transfected with a construct encompassing a luciferase reporter gene under the control of $1.4 \mathrm{~kb}$ of the rat MATIA 5' region, as described in Methods and as previously reported [10]. Transfected cells were treated with either DMSO (the vehicle in which 3-MC is dissolved) or with 3-MC at $5 \mu \mathrm{M}$, and then luciferase activity was measured in cellular lysates after $24 \mathrm{hr}$ of treatment. As shown in Fig. 5B, 3-MC treatment resulted in a 55\% reduction in 
A

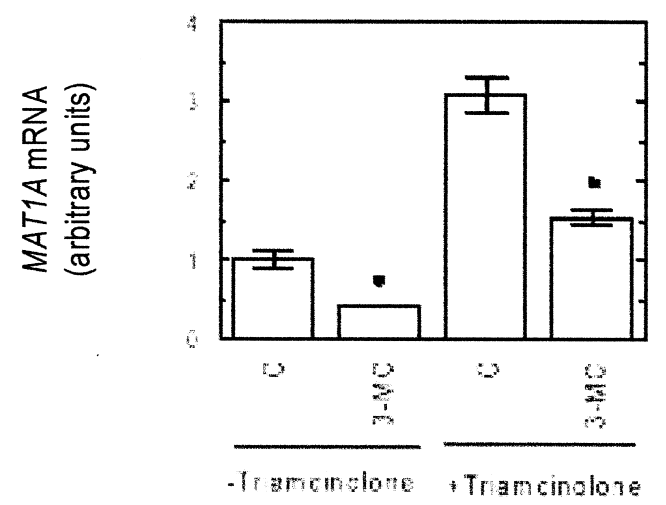

B

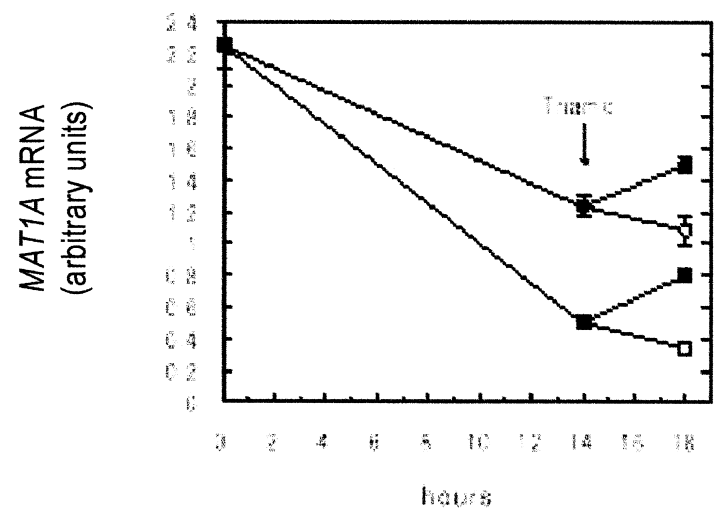

Fig. 4. 3-MC does not interfere with the glucocorticoid-mediated induction of MAT1A expression. (A) Effect of 3-MC on MAT1A expression in glucocorticoid-treated hepatocytes. Cells were incubated for $24 \mathrm{hr}$ with DMSO (controls) or 3-MC $(5 \mu \mathrm{M})$ in the presence or absence of $1 \mu \mathrm{M}$ triamcinolone, and MATIA mRNA levels were analyzed by Northern blotting ( $* P<0.05$ compared with the control value). (B) Effect of 3-MC pretreatment on the glucocorticoid-dependent induction of MAT1A expression in rat hepatocytes. Cells were preincubated for $14 \mathrm{hr}$ in the presence of DMSO (controls) (circles) or 3-MC (5 $\mu \mathrm{M})$ (squares). Half of the plates in each case then received a single dose of $1 \mu \mathrm{M}$ triamcinolone to induce MAT1A expression (closed circles and squares), while the other half remained untreated (open squares and circles). Incubation continued for a further $4 \mathrm{hr}$ and MATIA mRNA levels were analyzed by Northern blotting. Data are means \pm SEM of two independent experiments done in triplicate ( ${ }^{*} P<0.05$ compared with the control value in each case).

luciferase activity as compared with vehicle-treated controls. As specified in Methods, hepatocytes were cotransfected with a plasmid coding for $\beta$-galactosidase to monitor transfection efficiency and to assess the specificity of 3-MC effects. We recently reported that AdoMet plays a central role in the maintenance of MATIA expression in rat hepatocytes [10]. Although the mechanisms behind this effect of AdoMet are not completely known, this effect takes place at the transcriptional level and a methylation reaction seems to be involved [10]. We tested whether exogenously added AdoMet could prevent the down-regulation of MATIA expression mediated by 3-MC. Hepatocytes were transiently transfected with the above-mentioned MATIA promoterluciferase reporter vector, then cells were treated with 3-MC $(5 \mu \mathrm{M})$ for $24 \mathrm{hr}$ in the presence or absence of AdoMet (2 $\mathrm{mM}$ ), and luciferase activity was measured. As shown in Fig. 5B, AdoMet prevented the down-regulation of reporter gene expression driven by the MATIA promoter. We next examined if this effect of AdoMet on MAT1A promoter down-regulation by 3-MC could be observed at the mRNA level. For this purpose, cultured hepatocytes were incubated with 3-MC $(5 \mu \mathrm{M})$ in the presence or absence of AdoMet (4 $\mathrm{mM}$ ) for $24 \mathrm{hr}$, and MATIA mRNA levels were then measured. As shown in Fig. 5C, and as reported [10], AdoMet treatment resulted in higher levels of MATIA mRNA when compared with controls. When cells were treated with 3-MC $(5 \mu \mathrm{M}, 24 \mathrm{hr})$ in the presence of AdoMet $(4 \mathrm{mM})$, the down-regulation of MATIA mRNA levels was totally prevented (Fig. 5C). This is in agreement with the results obtained in the transfection experiments shown in Fig. 5B. A similar response was observed when hepatocytes were first treated with 3-MC $(5 \mu \mathrm{M})$ for $12 \mathrm{hr}$, and then AdoMet $(4 \mathrm{mM})$ was added to the culture medium and incubation continued for another $12 \mathrm{hr}$. Under these conditions, MATIA mRNA levels recovered to levels equivalent to cells treated with AdoMet without preincubating with the xenobiotic (Fig. 5D). Interestingly, AdoMet did not prevent the induction of CYP1Al mRNA by 3-MC (data not shown).

\section{Discussion}

In the liver, methionine metabolism starts with the formation of AdoMet, a reaction catalyzed by MAT I/III. This is the preferred catabolic route for this amino acid, and represents the first step of a metabolic pathway also known as the methionine cycle. This pathway leads to the provision of methyl groups (one-carbon units) for methylation reactions, precursors for polyamine and GSH biosynthesis, and sulfate groups for xenobiotic detoxication $[1,2,4]$. An adequate supply of one-carbon units to the liver is essential for the preservation of its differentiated functions. When the flow of one-carbon units is impaired due to severe dietary restrictions or to liver damage, many of the tissue-specific functions of this organ are compromised and can be subsequently lost in a transition to a preneoplastic condition. An early biochemical event in these situations is the reduced availability of AdoMet, which may be due to a shortage of its precursor (as in methionine/choline-deficient diets) [39], impaired synthesis because of the inactivation of MAT I/III or impaired MATIA expression, or the overall derangement of the methionine cycle [4-6,40]. The beneficial effects of AdoMet administration in such situations, which include the prevention of the neoplastic conversion of the liver, further support the importance of this metabolic pathway and a role 
A

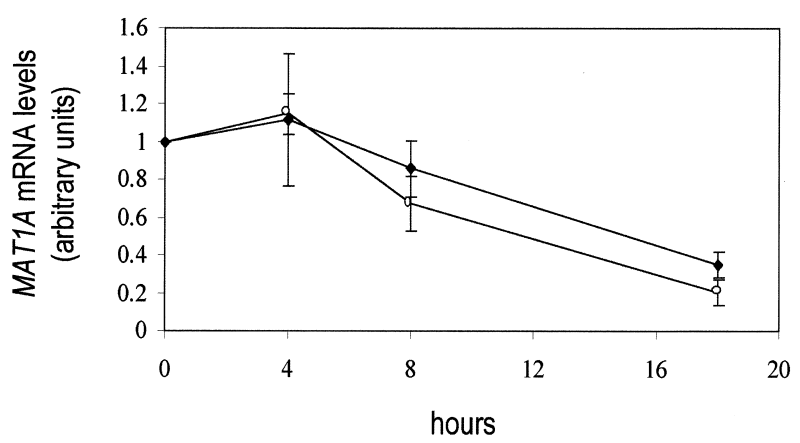

$\mathrm{C}$

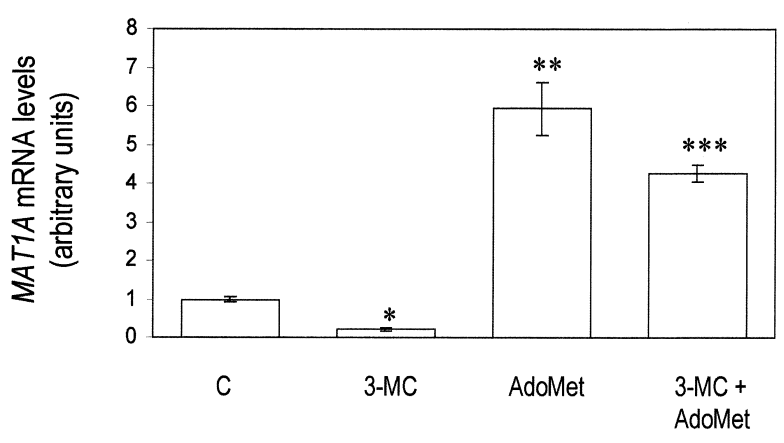

B

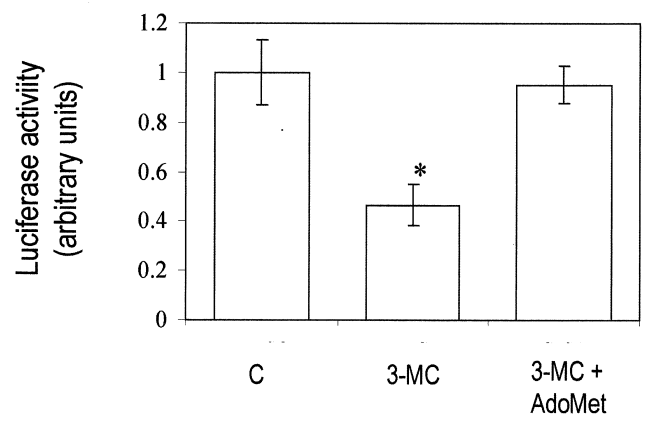

$\mathrm{D}$

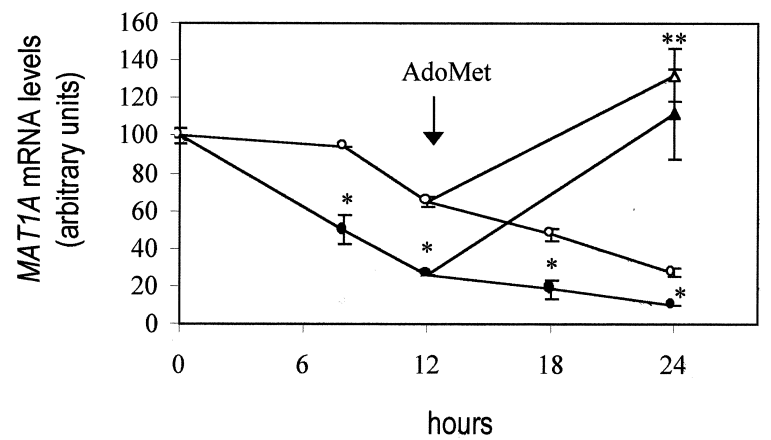

Fig. 5. Mechanism of MAT1A mRNA down-regulation by 3-MC. Effect of AdoMet treatment. (A) Effect of 3-MC MAT1A mRNA stability in cultured hepatocytes. Cells were treated for $2 \mathrm{hr}$ with ActD $(5 \mu \mathrm{g} / \mathrm{mL})$, and then 3-MC ( $5 \mu \mathrm{M})$ or DMSO (controls) was added to the culture medium and incubations continued for the indicated periods of time. MAT1A mRNA levels were measured in 3-MC-treated cells (open circles) and in controls (closed diamonds) by Northern blotting. 18S rRNA hybridization was performed as loading control. Data are means \pm SEM of two independent experiments done in triplicate. (B) Effect of 3-MC on MAT1A promoter-driven transcription. Hepatocytes were transfected with a construction containing a luciferase reporter gene under the control of the rat MAT1A promoter (see Materials and Methods for details). After transfection, cells were incubated for $24 \mathrm{hr}$ in the presence of DMSO (controls), 3-MC $(5 \mu \mathrm{M})$, or 3-MC plus AdoMet $(2 \mathrm{mM})$, and luciferase activity was then assayed. Data are means \pm SEM of three independent experiments done in triplicate ( ${ }^{*} P<0.05$ compared with the control value). (C) AdoMet treatment prevents the reduction in MAT1A mRNA levels induced by 3-MC. Hepatocytes were incubated for $24 \mathrm{hr}$ with DMSO (controls), AdoMet $(4 \mathrm{mM}), 3-\mathrm{MC}(5 \mu \mathrm{M})$, or both agents simultaneously, and then MAT1A mRNA levels were determined by Northern blotting $(* P<0.05$ compared with the control value, $* * P<0.05$ compared with the control value, $* * * P<0.05$ compared with 3-MC value). (D) AdoMet reverses the effect of 3-MC on MAT1A mRNA levels in cultured hepatocytes. Hepatocytes were incubated in the absence (controls) (open circles) or presence (closed circles) of $5 \mu \mathrm{M} 3-\mathrm{MC}$, and after $12 \mathrm{hr}$ AdoMet (4 mM) was added to half of the plates for each condition. MAT1A mRNA levels in cells treated (closed triangles) or untreated (open triangles) with 3-MC were determined $12 \mathrm{hr}$ after the addition of AdoMet (*P< 0.05 compared with control values, $* * P<0.05$ compared with values obtained in cultures without AdoMet treatment). Data are means \pm SEM of three independent experiments done in triplicate.

for this compound in the maintenance of liver functions $[4,9,41,42]$.

These notions led us to study herein whether MATIA gene expression could be targeted by xenobiotic agents such as PAHs. These compounds are extensively metabolized in the liver, and have been shown to impair certain metabolic pathways $[13,14]$ and to potentiate the deleterious effects of hepatotoxic agents such as paracetamol [15]. We have observed that 3-MC administration to rats led to a significant reduction in liver MATIA steady-state mRNA levels after four days of daily oral administration. The reduction in MATIA mRNA levels was accompanied by the induction of the expression of CYP1A1, a well-characterized xenobiotic- responsive gene [18]. In order to demonstrate whether the observed response of the MATIA gene was a direct effect of 3-MC on the hepatic parenchyma and not just the consequence of any other systemic interaction of this agent, further experiments were carried out in isolated cultured rat hepatocytes. Data collected in this experimental setting indicated that liver MATIA is indeed targeted by 3-MC. MATIA mRNA and MAT I/III protein levels were downregulated in a dose- and time-dependent fashion. In addition, MATIA expression was also inhibited by $\mathrm{B}[a] \mathrm{P}$, a carcinogen of the PAH group and a widespread environmental pollutant. The simultaneous induction of CYPIA1 mRNA was observed in response to $3-\mathrm{MC}$ and $\mathrm{B}[a] \mathrm{P}$, 
indicating that the decrease in MATIA expression was specific and not the consequence of an overall derangement of the cellular gene transcription machinery by PAH treatment. It was important to know whether 3-MC-mediated downregulation of MATIA expression involved the ligand-dependent transcription factor AhR, which is responsible for most of the gene-regulatory effects of this kind of compounds [43]. To this end, we treated cultured hepatocytes with a high dose of the potent AhR agonist TCDD and found that MATIA mRNA levels were unaffected, while there was a marked induction of CYPIAl expression. In addition, we observed that the AhR antagonist $\alpha$-NF [35] did not interfere with the effect of 3-MC on MATIA mRNA downregulation. All this suggested that the AhR was not implicated in the observed effect of 3-MC on MATIA expression. Alternative mechanisms have been proposed to explain the effects of PAHs on gene expression $[24,44,45]$. Other protein receptors for this family of compounds have been characterized. Such is the case of the PAH-binding protein, also known as the $4 \mathrm{~S}$ receptor, according to its sedimentation in the $4 \mathrm{~S}$ fraction of sucrose density gradients [46]. This receptor has been identified as glycine $N$-methyltransferase, although this is still a controversial issue $[47,48]$. The $4 \mathrm{~S}$ receptor does not bind TCDD, and certain PAHs that are not ligands of the $\mathrm{AhR}$, such as $\mathrm{B}[e] \mathrm{P}$, have been shown to induce CYPIAl gene expression through binding to this receptor $[45,46]$. Our observation that $\mathrm{B}[e] \mathrm{P}$, but not TCDD, down-regulated MATIA expression may suggest that the $4 \mathrm{~S}$ receptor could play a role in this process.

The generation of free radicals and the concomitant reduction of intracellular GSH levels has been proposed as another mechanism activated by 3-MC and other chemical agents which may influence gene expression [37,38]. For instance, this has been demonstrated for the 3-MC-mediated up-regulation of the glutathione $S$-transferase $Y a$ gene, which can be abolished in the presence of reducing agents [37]. Our present evidence regarding MATIA regulation by 3 -MC indicates that this gene is not responsive to variations in the prooxidant status of the hepatocytes, as suggested by the lack of protection from 3-MC effects by reducing agents such as NAC and EGSH.

Certain xenobiotics have been shown to impair glucocorticoid actions in vivo and in cultured hepatocytes. 3-MC has been demonstrated to affect the activities of glucocorticoid hormone-regulated enzymes in rat liver, probably through the functional decrease of the cytosolic glucocorticoid receptor $[26,49]$. Glucocorticoid hormones are potent stimulators of MATIA expression in rat liver [36]. In the case of MATIA, we have excluded this possibility by showing that 3 -MC was active in vitro in the absence of glucocorticoids and that the presence of 3-MC did not impair MATIA responsiveness to this hormone. In addition, other xenobiotics such as phenobarbital and TCDD have been shown to equally impair glucocorticoid receptor functions [26], although these compounds were without effect on MAT1A gene expression.
Down-regulation of MATIA expression by 3-MC seems to take place at the transcriptional level. This can be inferred by the lack of effect of this PAH on MATIA mRNA stability, while transcription from a MATIA promoter-reporter construct was inhibited by $3-\mathrm{MC}$. However, the precise promoter element or elements involved in this response to 3-MC are not yet known, and we cannot rule out the possibility that this effect was mediated through an indirect mechanism. As previously mentioned, we have recently shown that AdoMet plays a key role in the maintenance of MATIA gene expression in rat hepatocytes, with this effect taking place at the transcriptional level and involving a methylation reaction [10]. We and others have shown that by increasing extracellular AdoMet concentration above certain levels, the intracellular pool of this compound can be increased [10,50,51]. Now we observe that by adding AdoMet to 3-MC-treated cells, the down-regulation of MATIA mRNA steady-state levels and promoter activity can be prevented. Furthermore, AdoMet was able to reverse the effect of 3-MC on MATIA expression when this compound was added to hepatocytes that had been pretreated for $12 \mathrm{hr}$ with 3-MC. In our in vivo experiments, MATlA mRNA was reduced in response to 3-MC, while the hepatic levels of AdoMet were not yet significantly different from controls. This observation suggests that 3-MC could interfere with AdoMet-mediated induction of MATIA expression, before the cellular concentrations of this metabolite fall due to decreased MAT I/III protein synthesis. It is known that 3-MC, and other PAHs such as $\mathrm{B}[a] \mathrm{P}$ and $\mathrm{B}[e] \mathrm{P}$, are metabolized in the liver to reactive electrophiles [52]. As these positively charged intermediaries bear a formal resemblance to the positively charged AdoMet molecule, competition for the same intracellular site, which may be a methyltransferase enzyme, may ensue. In this regard, it has been demonstrated that the mammalian methyltransferase that catalyzes DNA methylation can be inhibited by reactive $\mathrm{B}[a] \mathrm{P}$ metabolites [53]. This hypothesis may also contribute to explain the differential effects of PAHs (3$\mathrm{MC}, \mathrm{B}[a] \mathrm{P}$, and $\mathrm{B}[e] \mathrm{P})$ and the dioxin TCDD on MATlA expression in the hepatocyte: while these PAHs can be metabolized to charged reactive intermediates, the dioxin TCDD does not seem to be.

In summary, we have identified the MATIA gene as a novel target for PAH action in rat liver. Given the central role played by AdoMet in cellular metabolism, the preservation of MATIA expression, and thus of AdoMet synthesis, is essential for the maintenance of liver functions. Exposure to PAHs, which can be found in tobacco smoke, coal tar, air pollutants, and petroleum [12], may compromise the hepatic availability of AdoMet, and consequently make this organ more sensitive to other well-known hepatotoxic agents such as ethanol and paracetamol. In addition, our present observations on the effect of AdoMet on the down-regulation of MAT1A gene expression by PAHs provide novel insights into the mechanisms of the hepatoprotective action of this molecule. 


\section{Acknowledgments}

This work was supported by Grants SAF 98/0132, SAF 99/0038 from CICYT (Spain), by Europharma and Knoll, and Grants 923/1998 and 681/2000 from the Gobierno de Navarra (Spain). M.V.C. and E.R.G.T. are fellows of the Universidad de Navarra. M.U.L. is a fellow of the Fundación Renal Iñigo Alvarez de Toledo. We thank Estefanía Fernández and Carmentxu Miqueo for their technical help.

\section{References}

[1] Finkelstein JD. Methionine metabolism in mammals. J Nutr Biochem 1990;1:228-37.

[2] Meister A, Anderson ME. Glutathione. Annu Rev Biochem 1983;52: 711-60.

[3] Kotb M, Mudd SH, Mato JM, Geller AM, Kredich NM, Chou JY, Cantoni GL. Consensus nomenclature for the mammalian methionine adenosyltransferase genes and gene products. Trends Genet 1997;13: $51-2$.

[4] Mato JM, Alvarez L, Ortiz P, Pajares MA. S-Adenosylmethionine synthesis: molecular mechanisms and clinical implications. Pharmacol Ther 1997;73:265-80.

[5] Avila MA, Berasain C, Torres L, Martín-Duce A, Corrales FJ, Yang H, Prieto J, Lu SC, Caballería J, Rodés J, Mato JM. Reduced mRNA abundance of the main enzymes involved in methionine metabolism in human liver cirrhosis and hepatocellular carcinoma. J Hepatol 2000;33:907-14.

[6] Avila MA, Carretero MV, Rodriguez EN, Mato JM. Regulation by hypoxia of methionine adenosyltransferase activity and gene expression in rat hepatocytes. Gastroenterology 1998;114:364-71.

[7] Poirier LA, Grantham PH, Rogers AE. The effects of a marginally lipotrope-deficient diet on the hepatic levels of $S$-adenosylmethionine and on the urinary metabolites of 2-acetylaminofluorene in rats. Cancer Res 1977;37:744-8.

[8] Buehring YS, Poirier LA, Stokstad EL. Folate deficiency in the livers of diethylnitrosamine-treated rats. Cancer Res 1976;36:2775-9.

[9] Mato JM, Camara J, Fernandez de Paz J, Caballeria L, Coll S, Caballero A, Garcia-Buey L, Beltran J, Benita V, Caballeria J, Sola R, Moreno-Otero R, Barrao F, Martin-Duce A, Correa JA, Pares A, Barrao E, Garcia-Magaz I, Puerta JL, Moreno J, Boissard G, Ortiz P, Rodés J. S-Adenosylmethionine in alcoholic liver cirrhosis: a randomized, placebo-controled, double-blind, multicenter clinical trial. J Hepatol 1999;30:1081-9.

[10] García-Trevijano ER, Latasa MU, Carretero MV, Berasain C, Mato JM, Avila MA. S-Adenosylmethionine regulates MAT1A and MAT2A gene expression in cultured rat hepatocytes: a new role for $S$-adenosylmethionine in the maintenance of the differentiated status of the liver. FASEB J 2000;14:2511-8.

[11] Torres L, Avila MA, Carretero MV, Latasa MU, Caballería J, LópezRodas G, Boukaba A, Lu SC, Franco L, Mato JM. Liver-specific methionine adenosyltransferase MATIA gene expression is associated with a specific pattern of promoter methylation and histone acetylation: implications for MAT1A silencing during transformation. FASEB J 2000;14:95-102.

[12] Williams GM, Weisburger JH. Chemical carcinogenesis. In: Amdur MO, Doull J, Klassen CD, editors. Casarett and Doull's toxicologyThe basic science of poisons, 4th Edn. New York: Pergamon, 1991. p. $172-4$.

[13] Sastry BV, Statham CN, Meeks RG, Axelrod J. Changes in phospholipid methyltransferases and membrane microviscosity during induction of rat liver microsomal cytochrome P-450 by phenobarbital and 3-methylcholanthrene. Pharmacology 1981;23:211-22.
[14] Ishidate K, Tsuruoka M, Nakazawa Y. Induction of choline kinase by polycyclic aromatic hydrocarbons in rat liver. II. Its relation to net phosphatidylcholine biosynthesis. Biochim Biophys Acta 1982;14: 103-11.

[15] Szymanska JA, Swietlicka EA, Piotrowski JK, Skrzypinska-Gawrysiak M, Sporny S. Effects of 3-methylcholanthrene or diethyl maleate on the hepatotoxicity of acetaminophen. J Appl Toxicol 1992;12: $415-9$.

[16] Okey AB, Riddick DS, Harper FA. Molecular biology of the aromatic hydrocarbon (dioxin) receptor. Trends Pharmacol Sci 1994;15:22632.

[17] Whitlock JP. The aromatic hydrocarbon receptor, dioxin action, and endocrine homeostasis. Trends Endocrinol Metab 1994;5:183-8.

[18] Whitlock JP. Induction of cytochrome P4501A1. Annu Rev Pharmacol Toxicol 1999;39:103-25.

[19] Carrière V, Dussaulx E, Rousset M, Zwebaum A, Cambier D. Decreased expression of $\gamma$-glutamyltranspeptidase in the intestinal cell line Caco-2 by inducers of cytochrome P450 1A1. Biochem Pharmacol 1998;56:817-23.

[20] Guengerich FP, Dannan GA, Wright ST, Martin MV, Kaminsky KS. Purification and characterization of liver microsomal cytochromes P-450: electrophoretic, spectral, catalytic, and immunochemical properties and inducibility of eight isozymes isolated from rats treated with phenobarbital or $\alpha$-naphtoflavone. Biochemistry 1982;21:601930.

[21] Yeowell HN, Waxman DJ, Wadhera A, Goldstein JA. Suppression of the constitutive, male-specific rat hepatic cytochrome P-450 2c and its mRNA by $3,4,5,3^{\prime}, 4^{\prime}, 5^{\prime}$-hexachlorobiphenyl and 3-methylcholanthrene. Mol Pharmacol 1987;32:340-7.

[22] Shimada M, Murayama N, Yamauchi K, Yamazoe Y, Kato R. Suppression in the expresssion of a male-specific cytochrome $\mathrm{P} 450$, P450-male: difference in the effect of chemical inducers on P450male mRNA and protein in rat livers. Arch Biochem Biophys 1989; 270:578-87.

[23] Jones EJ, Riddick DS. Regulation of constitutive rat hepatic cytochromes P450 by 3-methylcholanthrene. Xenobiotica 1996;26:9951012.

[24] Timsit YE, Riddick DS. Interference with growth hormone stimulation of hepatic cytochrome $\mathrm{P} 4502 \mathrm{C} 11$ expression in hypophysectomized male rats by 3-methylcholanthrene. Toxicol Appl Pharmacol 2000;163:105-14.

[25] Runge-Morris M, Wilusz J. Suppression of hydroxysteroid sulfotransferase-a gene expression by 3-methylcholanthrene. Toxicol Appl Pharmacol 1994;125:133-41.

[26] Sunhara GI, Guenat C, Grieu F. Characterization of 3-methylcholanthrene effects on the rat glucocorticoid receptor in vivo. Cancer Res 1989;49:3535-41.

[27] Corrales F, Giménez A, Alvarez L, Caballería J, Pajares MA, Andreu H, Pares A, Mato JM, Rodes J. S-Adenosylmethionine treatment prevents $\mathrm{CCl}_{4}$-induced $S$-adenosylmethionine synthetase inactivation and attenuates liver injury. Hepatology 1992;16:1022-7.

[28] Chomczynski P, Sacchi N. Single-step method of RNA isolation by acid guanidinium thiocyanate-phenol-chloroform extraction. Anal Biochem 1987;162:156-9.

[29] Avila MA, Velasco JA, Cho C, Lupu R, Wen D, Notario V. Hyperactive autocrine loop mediated by a NDF-related factor in neoplastic hamster embryo fibroblasts expressing an activated $\mathrm{cph}$ oncogene. Oncogene 1995;10:963-71.

[30] Alvarez L, Asuncion M, Corrales F, Pajares MA, Mato JM. Analysis of the $5^{\prime}$ non-coding region of rat liver $S$-adenosylmethionine mRNA and comparison of the $M_{r}$ deduced from the cDNA sequence and the purified enzyme. FEBS Lett 1991;290:142-6.

[31] Gonzalez FJ, Mackenzie PI, Kimura S, Nebert DW. Isolation and characterization of full-length mouse cDNA and genomic clones of 3-methylcholanthrene-inducible cytochrome P1-450 and P3-450. Gene 1984;29:281-92. 
[32] Ruiz F, Corrales FJ, Miqueo C, Mato JM. Nitric oxide inactivates rat hepatic methionine adenosyltransferase in vivo by $S$-nitrosilation. Hepatology 1998;28:1051-7.

[33] Alvarez L, Sánchez-Góngora E, Mingorance J, Pajares MA, Mato JM. Characterization of rat liver-specific methionine adenosyltransferase gene promoter. J Biol Chem 1997;272:22875-83.

[34] Clayton DF, Darnell JE. Changes in liver-specific compared to common gene transcription during primary culture of mouse hepatocytes. Mol Cell Biol 1983;3:1552-61.

[35] Krishnan V, Porter W, Santostefano M, Wang X, Safe S. Molecular mechanism of inhibition of estrogen-induced cathepsin D gene expression by 2,3,7,8-tetrachlorodibenzo- $p$-dioxin (TCDD) in MCF-7 cells. Mol Cell Biol 1995;15:6710-9.

[36] Gil B, Pajares MA, Mato JM, Alvarez L. Glucocorticoid regulation of hepatic $S$-adenosylmethionine synthetase gene expression. Endocrinology 1997;138:1251-8.

[37] Bergelson S, Pinkus R, Daniel V. Intracellular glutathione levels regulate Fos/Jun induction and activation of glutathione $S$-transferase gene expression. Cancer Res 1994;54:36-40.

[38] Dalton TP, Shertzer HG, Puga A. Regulation of gene expression by reactive oxygen. Annu Rev Pharmacol Toxicol 1999;39:67-101.

[39] Newberne PM, Rogers AE. Labile methyl groups and the promotion of cancer. Annu Rev Nutr 1986;6:407-32.

[40] Avila MA, Mingorance J, Martinez-Chantar ML, Casado M, MartinSanz P, Bosca L, Mato JM. Regulation of rat liver $S$-adenosylmethionine synthetase during septic shock: role of nitric oxide. Hepatology 1997;25:391-6.

[41] Pascale RM, Marras V, Simile MM, Daino L, Pinna G, Bennati S, Carta M, Seddaiu MA, Massarelli G, Feo F. Chemoprevention of rat liver carcinogenesis by $S$-adenosyl-L-methionine: a long-term study. Cancer Res 1992;52:4979-86.

[42] Chawla RK, Watson WH, Eastin CE, Lee EY, Schmidt J, McClain CJ. S-Adenosylmethionine deficiency and TNF-alpha in lipopolysaccharide-induced hepatic injury. Am J Physiol 1998;275:G125-9.
[43] Hankinson O. The aryl hydrocarbon receptor complex. Annu Rev Pharmacol Toxicol 1995;35:307-40.

[44] Hoffer A, Chang CY, Puga A. Dioxin induces transcription of fos and jun genes by Ah receptor-dependent and -independent pathways. Toxicol Appl Pharmacol 1996;141:238-47.

[45] Ainbinder E, Bergelson S, Daniel V. Signaling pathways in the induction of c-fos and c-jun proto-oncogenes by 3-methylcholanthrene. Recept Signal Transduct 1998;7:279-89.

[46] Sterling K, Raha A, Bresnick E. Induction of CYP1A1 gene expression in mouse hepatoma cells by benzo[ $e]$ pyrene, a ligand of the $4 \mathrm{~S}$ polycyclic hydrocarbon-binding protein. Toxicol Appl Pharmacol 1994;128:18-24.

[47] Bhat R, Bresnick E. Glycine $N$-methyltransferase is an example of functional diversity. Role as polycyclic aromatic hydrocarbon-binding receptor. J Biol Chem 1997;272:21221-6.

[48] Ogawa H, Gomi T, Imamura T, Kobayashi M, Huh N. Rat liver 4S-benzo[ $a]$ pyrene-binding protein is distinct from glycine $N$-methyltransferase. Biochem Biophys Res Commun 1997;233:300-4.

[49] Boll M, Weber LW, Font M, Stampfl A. The enzyme inducers 3-methylcholanthrene and phenobarbital affect the activities of glucocorticoid hormone-regulated enzymes in rat liver and kidney. Toxicology 1998;126:127-36.

[50] Watson WH, Zhao Y, Chawla RK. S-Adenosylmethionine attenuates the lipopolysaccharide-induced expression of the gene for tumour necrosis factor- $\alpha$. Biochem J 1999;342:21-5.

[51] Bontemps F, Van Den Berghe G. Metabolism of exogenous $S$-adenosylmethionine in isolated rat hepatocyte suspensions: methylation of plasma-membrane phospholipids without intracellular uptake. Biochem J 1997;327:383-9.

[52] Dipple A, Lawley PD, Brookes P. Theory of tumour initiation by chemical carcinogens: dependence of activity on structure of ultimate carcinogen. Eur J Cancer 1968;4:493-506.

[53] Wojciechowski MF, Meehan T. Inhibition of DNA methyltransferases in vitro by benzo $[a]$ pyrene diol epoxide-modified substrates. J Biol Chem 1984;259:9711-6. 